\title{
Modeling and Diagnosis of the Inter-Turn Short Circuit Fault for the Sensorless Input-Output Linearization Control of the PMSM
}

\author{
Yacine Maanani ${ }^{1 *}$, Arezki Menacer ${ }^{1}$ \\ 1 LGEB Laboratory, Department of Electrical Engineering, Faculty of Science and Technology, University of Biskra, \\ Biskra University, BP 145, Biskra 07000, Algeria \\ * Corresponding author, e-mail: yacine.maanani@gmail.com
}

Received: 29 December 2018, Accepted: 11 February 2019, Published online: 27 March 2019

\begin{abstract}
The purpose of this paper is the inter-turn short circuit fault Modeling and detection for the sensorless input-output linearization control of the permanent magnet synchronous motor (PMSM) based on the Extended Kalman Filter observer (EKF). The fault detection procedures are based through the estimation of the stator resistance variation by the Extended Kalman Filter observer and the Fast Fourier Transformer (FFT) for the stationary state, and the Discrete Wavelet Transform (DWT) analysis of the electrical characteristics of the PMSM, for the non-stationary state. However, the FFT spectral analysis and the DWT is a useful solution to ensure that the variation of the stator resistance estimation is caused by the inter-turn short circuit fault. The effectiveness of the sensorless control and the fault detection techniques are presented in a simulation in MATLAB/Simulink environment.
\end{abstract}

Keywords

permanent magnet synchronous machine (PMSM), inter-turn short circuit, sensorless input-output control, fault detection, extended kalman filter (EKF), stator resistance estimation, FFT, DWT

\section{Introduction}

The Permanent Magnet Synchronous Machines (PMSMs) are awarding a high attention in robotics, automotive and electric traction due to their high efficiency, high power density and their relevance for high-performance applications by the progress in the permanent magnet materials $[1,2]$. For the electric motors, the faults or failures usually lead to serious consequences, such as intemperate downtimes, prohibitive maintenance costs, and even human casualties. The early fault detection helps in reducing the machine's maintenance cost and time. Therefore, research effort on the PMSM fault diagnosis has been on the rise [3].

The possible fault modes in the PMSM include the electrical and mechanical sources. Statistics demonstrate that over than $47 \%$ of the electric motor failures are due to electrical faults. Among them, the stator winding faults, which represent the largest portion and the most important causes of faults in the PMSM [4]; hence, an effective fault diagnosis is necessary to ameliorate the reliability of such motors. The early methods used noise, temperature, and vibration analysis [5, 6]. However, these methods are quite expensive and its mechanical installation is sensitive to the noise.
The motor current signature analysis (MCSA) method has some advantages, like its simplicity of current measurement and its base on simple signal processing techniques, such as the Fast Fourier transform (FFT) or similar harmonic calculation procedures [7, 8]. The FFT analysis method is used to characterize the different kinds of the short-circuit faults, and it can be applied when the frequency is constant, unlike other algorithms which can be used in a variable speed or in a transient state, like the Wigner Ville Distribution (WVD) and the Wavelet Transform (WT) [9, 10].

The Wavelet theory provides a unified framework for a number of techniques which have been developed for various signal processing applications. The DWT is based on the decomposition of the signal on a basis of particular functions [11, 12]. In a variable speed control drives, the diagnosis is delicate, because the fault may appear as a disturbance for the control-loop, where the used InputOutput Linearization control corrects and compensates the fault effect, and unlike the field oriented control, the nonlinear control permits decoupling and linearizing the system without taking into account the flux orientation [13]. 
In the closed-loop case, the diagnosis by the approach model parametric is, therefore, necessary using observers. Multiple structures of observers have been suggested in the literature: MRAS, sliding mode observer, Luenberger observer and Extended Kalman Filter (EKF) [14, 15]. The EKF is a stochastic observer awarding the best optimal estimation of states or parameters for the nonlinear systems. Many researchers have focused their attention on the uses of the EKF observer for the fault detection [16, 17].

The main objective of this paper is the detection of the inter-turn short circuit fault for the permanent magnet synchronous machine driven by the sensorless input-output linearization control using the EKF observer. Three procedures of diagnosis are considered, the EKF for the stator resistance estimation while the parameters' variation is considered, the FFT method is applied for the electrical characteristic (quadratic and stator phase current) of the PMSM in order to check if the variation is caused by the fault or by a perturbation. Finally, the DWT analysis was introduced to overcome the shortcomings of the FFT spectral analysis. The performance and the effectiveness of the proposed control and diagnosis approaches model have been investigated through the simulation results using MATLAB/Simulink software.

\section{Dynamic model of the PMSM with an inter-turn short circuit}

The stator winding faults indicate an insulation failure between two windings in the same phase or into different phases of the stator. Fig. 1 shows the inter-turn short circuit fault in the stator winding of the PMSM, where the fault has occurred in the phase $\left(a_{s}\right)$ and $\left(r_{f}\right)$ represents the fault resistance. The sub-windings $\left(a_{\mathrm{s} 1}\right)$ represent the healthy part and $\left(a_{s 2}\right)$ represent the faulty part of the phase winding [18].

The evolution of the fault resistance between $r_{f}=\infty$ and $r_{f}=0$ is very fast in most insulation materials. It's important to predict the inter-turn short circuit fault when it is not highly increasing and the fault resistance is still not very near to zero. Therefore, in the approach model, the fault resistance is included and the machine behavior with various fault resistances is studied.

\subsection{Model of the PMSM with an inter-turn short circuit fault in $a, b, c$ coordinates}

The voltage equations for the circuit of Fig. 1 can be written as:

$V_{s}=\left[R_{s}\right] \cdot\left[I_{s}\right]+\left[L_{s s}\right] \frac{d}{d t}\left[I_{s}\right]+\left[E_{s}\right]$.

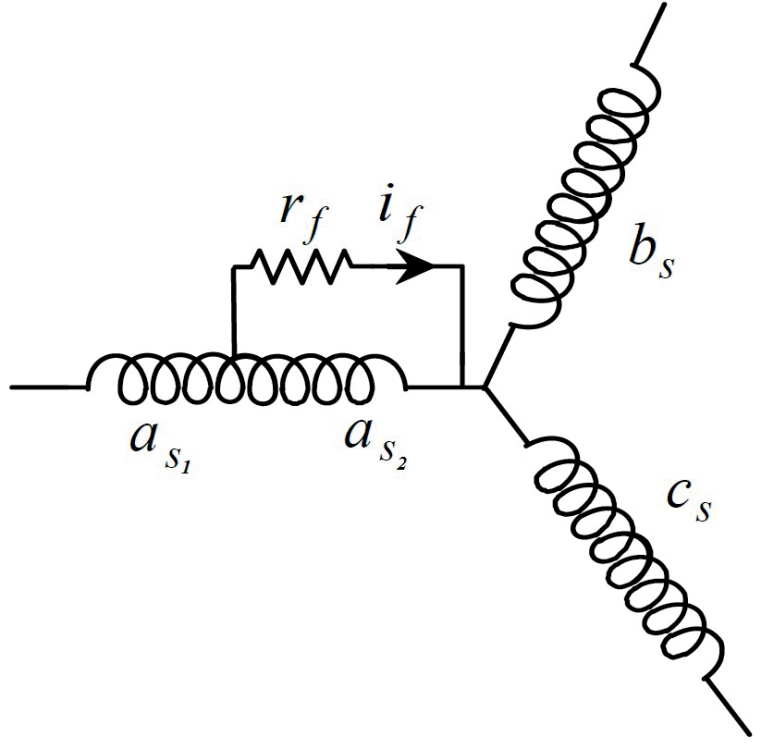

Fig. 1 Equivalent model of the PMSM with an inter-turn short fault in $a_{\mathrm{s}}$ phase

Where: $\left[V_{s}\right],\left[I_{s}\right]$ and $\left[E_{s}\right]$ are the stator voltage, current, and back-EMF vectors:

$V_{s}=\left[\begin{array}{lll}v_{a s} & v_{b s} & v_{c s}\end{array}\right]^{T} \quad I_{s}=\left[\begin{array}{lll}I_{a s} & I_{b s} & I_{c s}\end{array}\right]^{T} \quad E_{s}=\left[\begin{array}{lll}e_{a s} & e_{b s} & e_{c s}\end{array}\right]^{T}$.

$R_{s}$ is the phase resistance and $\left[L_{s s}\right]$ is the inductance matrix of the healthy state for the PMSM respectively:

$\left[R_{s}\right]=\left[\begin{array}{ccc}R_{s} & 0 & 0 \\ 0 & R_{s} & 0 \\ 0 & 0 & R_{s}\end{array}\right] \quad\left[L_{s s}\right]=\left[\begin{array}{ccc}L_{s} & M & M \\ M & L_{s} & M \\ M & M & L_{s}\end{array}\right]$.

Where $L_{s}$ is the self-inductance phase and $M$ is the mutual inductance between the phase windings for the healthy state of the PMSM. $R_{a 2}$ and $L_{a 2}$ represent respectively the resistance and the inductance of the faulty sub coil $\left(a_{s 2}\right)$. The parameters $M_{a 1 a 2}, M_{a 2 b}$, and $M_{a 2}$ represent respectively the mutual inductances between the subcoil $\left(a_{s 2}\right)$ and the coils $\left(a_{s 1}\right),\left(b_{s}\right)$ and $\left(c_{s}\right)$. The fault current through the fault resistance $r_{f}$ is also called $i_{f}$. For the machine having one slot per pole and per phase, $M_{a 2 b}$ can be considered equal to $M_{a 2 c}$.

The voltage equation of the faulty loop $\left(a_{s 2}\right)$ is:

$$
\begin{aligned}
0 & =-R_{a 2} I_{a s}-\left(L_{a 2}+M_{a 1 a 2}\right) \frac{d I_{a s}}{d t}-M_{a 2 b} \frac{d I_{b s}}{d t}-M_{a 2 c} \frac{d I_{c s}}{d t} \\
& -e_{a 2}+\left(R_{a 2}+r_{f}\right) I_{f}+L_{a 2} \frac{d I_{f}}{d t} .
\end{aligned}
$$


The equations of the voltages of the three phases are thus put in the form:

$$
\left\{\begin{array}{rl}
V_{a s}= & \left(R_{a 1}+R_{a 1}\right) I_{a s}+\left(L_{a 1}+L_{a 2}+2 M_{a 1 a 2}\right) \frac{d}{d t} I_{a s} \\
& +\left(M_{a 1 b}+M_{a 2 b}\right) \frac{d}{d t} I_{b s}+\left(M_{a 1 c}+M_{a 2 c}\right) \frac{d}{d t} I_{c s} \\
& +\left(e_{a 1}+e_{a 2}\right)-R_{a 2} I_{f}-\left(L_{a 2}+M_{a 1 a 2}\right) \frac{d}{d t} I_{f} \\
V_{c s}= & R_{s} I_{c s}+L \frac{d}{d t} I_{c s}+\left(M_{a 1 c}+M_{a 2 c}\right) \frac{d}{d t} I_{a s}+e_{c s} \\
& +M \frac{d}{d t} I_{b s}-M_{a 2 c} \frac{d}{d t} I_{f} \\
V_{b s}= & R I_{s}+L \frac{d}{d t} I_{b s}+\left(M_{a 1 b}+M_{a 2 b}\right) \frac{d}{d t} I_{a s}+e_{c s} \\
& +M \frac{d}{d t} I_{c s}-M_{a 2 b} \frac{d}{d t} I_{f}
\end{array} .\right.
$$

The following relations are normally allowed:

$$
\left\{\begin{array}{l}
R_{s}=R_{a}=R_{a 1}+R_{a 2} \\
L=L_{a 1}+L_{a 2}+2 M_{a 1 a 2} \\
M=M_{a 1 b}+M_{a 2 b} \\
M=M_{a 1 c}+M_{a 2 c} \\
e_{a}=e_{a 1}+e_{a 2}=e_{a 1}+e_{f}
\end{array} .\right.
$$

By replacing the above relations Eq. (4) in the electrical equations Eq. (3), the following matrix can be written:

$$
\begin{aligned}
{\left[\begin{array}{l}
V_{a s} \\
V_{b s} \\
V_{c s}
\end{array}\right]=} & R_{s}\left[\begin{array}{l}
I_{a s} \\
I_{b s} \\
I_{c s}
\end{array}\right]+\left[\begin{array}{ccc}
L_{s} & 0 & 0 \\
0 & L_{s} & 0 \\
0 & 0 & L_{s}
\end{array}\right] \frac{d}{d t}\left[\begin{array}{l}
I_{a s} \\
I_{b s} \\
I_{c s}
\end{array}\right]+\left[\begin{array}{l}
R_{a 2} \\
0 \\
0
\end{array}\right] I_{f} \\
& -\left[\begin{array}{l}
L_{a 2}+M_{a 1 a 2} \\
M_{a 2 b} \\
M_{a 2 c}
\end{array}\right] \frac{d I_{f}}{d t} .
\end{aligned}
$$

\subsection{Model of the PMSM with an inter-turn short circuit fault in $\alpha, \beta$ coordinates}

For the star connection of the windings, the zero sequence component of the stator current is zero. Thus, the transformation in the stator reference frame is applied:

$$
\left[\begin{array}{l}
x_{\alpha} \\
x_{\beta}
\end{array}\right]=\frac{2}{3}\left[\begin{array}{ccc}
1 & -\frac{1}{2} & -\frac{1}{2} \\
0 & \frac{\sqrt{3}}{2} & -\frac{\sqrt{3}}{2}
\end{array}\right]\left[\begin{array}{l}
x_{a} \\
x_{b} \\
x_{c}
\end{array}\right] .
$$

In $\alpha, \beta$ coordinates, the PMSM machine equations with an inter-turn winding fault are simplified as:

$$
\begin{aligned}
{\left[V_{\alpha \beta}\right] } & =R_{s}\left[I_{\alpha \beta}\right]+\left[L_{\alpha \beta}\right] \frac{d}{d t}\left[I_{\alpha \beta}\right]+\left[e_{\alpha \beta}\right] \\
& -\left[L_{0}^{\prime}\right] \frac{d}{d t}\left[I_{f}\right]-\left[R_{0}^{\prime}\right] I_{f} .
\end{aligned}
$$

For the faulty loop $\left(a_{s 2}\right)$, the voltage equation in $\alpha, \beta$ coordinates becomes:

$$
\begin{aligned}
0 & =-\sqrt{\frac{2}{3}} R_{a 2} I_{a s}-\sqrt{\frac{2}{3}}\left(L_{a 2}+M_{a 1 a 2}-\frac{M_{a 2 b}+M_{a 2 c}}{2}\right) \frac{d I_{a s}}{d t} \\
& -\frac{1}{\sqrt{2}}\left(M_{a 2 b}-M_{a 2 c}\right) \frac{d I_{b s}}{d t}-M_{a 2 c} \frac{d I_{c s}}{d t}-e_{a 2}+\left(R_{a 2}+r_{f}\right) I_{f} \\
& +L_{a 2} \frac{d I_{f}}{d t} .
\end{aligned}
$$

The final equations with an inter-turn fault in $\alpha, \beta$ reference frame are written as follows:

$$
\begin{aligned}
& {\left[\begin{array}{l}
V_{\alpha} \\
V_{\beta}
\end{array}\right]=R_{s}\left[\begin{array}{l}
V_{\alpha} \\
V_{\beta}
\end{array}\right]+L_{s} \frac{d}{d t}\left[\begin{array}{l}
I_{\alpha} \\
I_{\beta}
\end{array}\right]+\left[\begin{array}{l}
e_{\alpha} \\
e_{\beta}
\end{array}\right]-\sqrt{\frac{2}{3}}\left[\begin{array}{l}
R_{a 2} \\
0
\end{array}\right] I_{f}} \\
& -\left[\begin{array}{l}
\sqrt{\frac{2}{3}}\left(L_{a 2}+M_{a 1 a 2}-\frac{M_{a 2 b}+M_{a 2 c}}{2}\right) \\
\frac{1}{\sqrt{2}}\left(M_{a 2 b}-M_{a 2 c}\right)
\end{array}\right] \frac{d I_{f}}{d t} .
\end{aligned}
$$

or again:

$$
\begin{aligned}
{\left[\begin{array}{l}
V_{\alpha} \\
V_{\beta} \\
0
\end{array}\right]=} & {\left[\begin{array}{ccc}
R_{s} & 0 & -R_{a 2}^{\prime} \\
0 & R_{s} & 0 \\
-R_{a 2}^{\prime} & 0 & R_{f}^{\prime}
\end{array}\right]\left[\begin{array}{l}
I_{\alpha} \\
I_{\beta} \\
I_{f}
\end{array}\right] } \\
& +\left[\begin{array}{ccc}
L_{s} & 0 & M_{f a} \\
0 & L_{s} & 0 \\
M_{f a} & 0 & L_{a 2}
\end{array}\right] \frac{d}{d t}\left[\begin{array}{l}
I_{\alpha} \\
I_{\beta} \\
I_{f}
\end{array}\right]+\left[\begin{array}{l}
e_{\alpha} \\
e_{\beta} \\
-e_{f}
\end{array}\right] .
\end{aligned}
$$

with:

$$
\begin{aligned}
& R_{a 2}^{\prime}=\sqrt{\frac{2}{3}} R_{a 2}, R_{f}=R_{a 2}+r_{f}, e_{f}=e_{\alpha 2} \\
& M_{f a}=-\sqrt{\frac{2}{3}}\left(L_{a 2}+M_{a 1 a 2}-\frac{M_{a 2 b}+M_{a 2 c}}{2}\right), \\
& M_{f \beta}=\frac{1}{\sqrt{2}}\left(M_{a 2 b}-M_{a 2 c}\right) .
\end{aligned}
$$


Since the sequence component of the current is zero, the electromagnetic torque can be written as:

$T_{e}=\frac{e_{\alpha} I_{\alpha}+e_{\beta} I_{\beta}-e_{\alpha 2} I_{f}}{\Omega}$.

\subsection{State space form of the fault model of the PMSM}

The model of the machine with the inter-turn short circuit fault Eq. (10) can be written in the state space form:

$$
\begin{aligned}
\frac{d}{d t}\left[\begin{array}{c}
I_{\alpha} \\
I_{\beta} \\
I_{f}
\end{array}\right] & {\left[\begin{array}{ccc}
L_{s} & 0 & M_{f a} \\
0 & L_{s} & M_{f \beta} \\
M_{f a} & 0 & L_{a 2}
\end{array}\right]^{-1}\left(\left[\begin{array}{ccc}
-R_{s} & 0 & R_{a 2}^{\prime} \\
0 & -R_{s} & 0 \\
R_{a 2}^{\prime} & 0 & -R_{f}^{\prime}
\end{array}\right]\left[\begin{array}{c}
I_{\alpha} \\
I_{\beta} \\
I_{f}
\end{array}\right]\right) } \\
& +\left[\begin{array}{l}
v_{\alpha}-e_{\alpha} \\
v_{\beta}-e_{\beta} \\
e_{f}
\end{array}\right] .
\end{aligned}
$$

The state vector $(x)$ and the input vector $(u)$ are supposed as:

$$
x=\left[\begin{array}{l}
I_{\alpha} \\
I_{\beta} \\
I_{f}
\end{array}\right] ; \quad u=\left[\begin{array}{l}
v_{\alpha}-e_{\alpha} \\
v_{\beta}-e_{\beta} \\
e_{f}
\end{array}\right] .
$$

Thus, the machine fault model Eq. (12) in the state space form can be written as:

$\dot{x}=A x+B u$

with:

$$
\begin{aligned}
& A=-\left[\begin{array}{ccc}
L_{s} & 0 & M_{f a} \\
0 & L_{s} & M_{f \beta} \\
M_{f a} & 0 & L_{a 2}
\end{array}\right]^{-1}\left[\begin{array}{ccc}
R_{s} & 0 & -R_{a 2}^{\prime} \\
0 & R_{s} & 0 \\
-R_{a 2}^{\prime} & 0 & R_{f}^{\prime}
\end{array}\right], \\
& B=\left[\begin{array}{ccc}
L_{s} & 0 & M_{f a} \\
0 & L_{s} & M_{f \beta} \\
M_{f a} & 0 & L_{a 2}
\end{array}\right]^{-1} .
\end{aligned}
$$

\section{Input-Output linearization of the PMSM}

The linearization condition for checking whether the nonlinear system admits the input-output linearization is a relative degree of the system [19].

The degree relative to the output $y_{1}(x)$ is:

$$
\dot{y}(x)=\dot{h}_{1}(x)=L_{f d} h_{1}(x)+L_{g} h_{1}(x) U=f+g_{1} V_{d} .
$$

$X$ is the state vector and $f, g, h$ are the analytic functions.
The relative degree $r_{1}=1$ gives:

$\dot{y}_{2}(x)=\dot{h}_{2}(x)=L_{f} h_{2}(x)+L_{g} h_{2}(x) U=f_{3}$

where: $L_{g} h_{2}(x)=0$.

Then

$\dot{y}_{2}(x)=L_{f} h_{2}(x)=f_{3}$.

The second derivative of the output does not involve the input $U$; it must derive a second time the output:

The derivative of $h_{2}(x)$ dregs on $g$ are zero, the Eq. (13) can be written as:

$\ddot{y}_{2}(x)=\ddot{h}_{2}(x)=L_{f}^{22} h_{2}(x)+L_{f} L_{g} h_{2}(x) \cdot U$

with:

$$
\left\{\begin{array}{l}
L_{f}^{2} h_{2}(x)=f_{1} p \frac{\left(L_{d}-L_{q}\right)}{j} x_{2}+f_{2}\left(p \frac{\left(L_{d}-L_{q}\right)}{j} x_{1}+\frac{p \varphi_{f}}{j}\right) \\
-f_{3} \frac{f}{j} \\
L_{f} L_{g} h_{2}(x)=\left[\begin{array}{l}
\frac{1}{L_{d}} p \frac{\left(L_{d}-L_{q}\right)}{j} x_{2}+\frac{1}{L_{d}} p \frac{\left(L_{d}-L_{q}\right)}{j} x_{1} \\
+\frac{p \varphi_{f}}{j}
\end{array}\right]
\end{array} .\right.
$$

The relative degree for $y_{2}$ is $r_{2}=2$ and for the system is $r=r_{1}+r_{2}=3$.

The system is exactly linearizable $(r=n=3)$ where $\mathrm{n}$ is the order of the system.

Then the input-output relationship model is given by:

$$
\left[\begin{array}{l}
\dot{y}_{1}(x) \\
\ddot{y}_{2}(x)
\end{array}\right]=\left[\begin{array}{l}
\frac{d}{d t} I_{d} \\
\frac{d^{2}}{d t^{2}} \Omega
\end{array}\right]=A(x)+D(x)\left[\begin{array}{l}
V d \\
V q
\end{array}\right]
$$

or:

$$
\begin{aligned}
& A(x)=\left[\begin{array}{l}
f_{1} p \frac{\left(L_{d}-L_{q}\right)}{j} x_{2}+f_{2}\left(p \frac{\left(L_{d}-L_{q}\right)}{j} x_{1}+\frac{p \varphi_{f}}{j}\right) \\
-f_{3} \frac{f}{j}
\end{array}\right] \\
& D(x)=\left[\begin{array}{cc}
g_{1} & 0 \\
g_{1} p \frac{\left(L_{d}-L_{q}\right)}{j} x_{2} & g_{2} p \frac{\left(L_{d}-L_{q}\right)}{j} x_{1}+\frac{p \varphi_{f}}{j}
\end{array}\right] .
\end{aligned}
$$


If the determinant of the decoupling matrix is not equal to zero, the control condition (NL) is defined by a relationship that connects the new internal inputs $\left(V_{1}, V_{2}\right)$ to the physical inputs $\left(V_{d}, V_{q}\right)$.

$\left[\begin{array}{l}V_{d} \\ V_{q}\end{array}\right]=D^{-1}(x)\left[-A(x)+\left(\begin{array}{l}V_{1} \\ V_{2}\end{array}\right)\right]$.

$D$ : is the decoupling matrix.

By replacing the term for the Eq. (14) in Eq. (18), a linearized and decoupled system is obtained:

$\left[\begin{array}{l}\dot{y}_{1}(x) \\ \ddot{y}_{2}(x)\end{array}\right]=\left[\begin{array}{l}\frac{d}{d t} I_{d} \\ \frac{d^{2}}{d t^{2}} \Omega\end{array}\right]=\left[\begin{array}{l}V_{1} \\ V_{2}\end{array}\right]$.

\section{Non-linear control for the PMSM}

For checking whether a nonlinear system admits, an input-output linearization is one degree of the system [20]:

$V_{1}=K_{11}\left(I_{\text {dref }}-I_{d}\right)+\frac{d}{d t} I_{\text {dref }}$

or again:

$V_{1}=K_{22}\left(\Omega_{d r e f}-\Omega_{d}\right)+K_{21}\left(\frac{d \Omega_{d r e f}}{d t}-\frac{d \Omega}{d t}\right) \cdot \frac{d^{2} \Omega_{d r e f}}{d t^{2}}$.

In closed-loop, the tracking error is:

$\left\{\begin{array}{l}\frac{d}{d t} e_{1}+K_{11}=0 \\ \frac{d^{2}}{d t^{2}} e_{2}+K_{21} \frac{d}{d t} e_{2}+K_{22} e_{2}=0\end{array}\right.$

with:

$\left\{\begin{array}{l}e_{1}=I_{d r e f}-I_{d} \\ e_{2}=\Omega_{r e f}-\Omega_{d}\end{array}\right.$.

The coefficients $K_{11}, K_{21}, K_{22}$ are chosen so that:

$\left\{\begin{array}{l}P+k_{11}=0 \\ P^{2}+k_{21} P+k_{22}=0\end{array}\right.$.

\section{Extended Kalman filter observer (EKF)}

The Extended Kalman Filter is a mathematical tool capable of determining the quantities of the non-measurable scalable states, or stating the system's parameters from the physical measurable magnitudes. In addition, the state's measurements must show an uncorrelated noise, such as the permanent magnet synchronous motor model [21]. Fig. 2 shows the structure of the Kalman Filter observer [22].

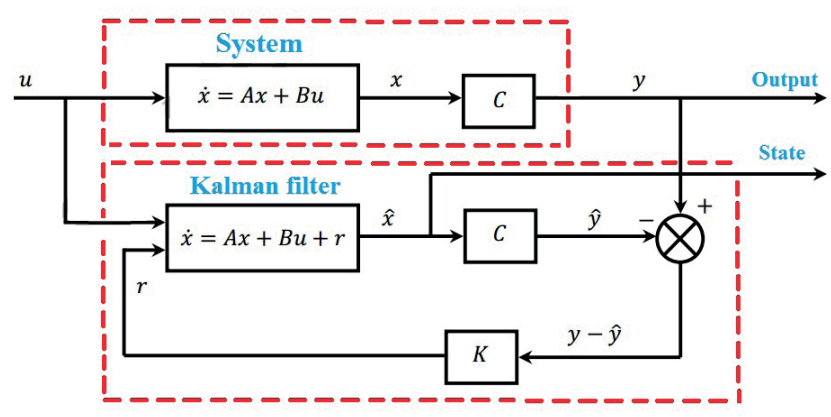

Fig. 2 Structure of the kalman filter observer

The nonlinear stochastic systems are described by:

$\left\{\begin{array}{l}\dot{x}=f(x, u)+w(t) \quad(\text { System }) \\ y=C x+v(t) \quad \text { (Measurement) }\end{array}\right.$.

Where: $x$ is the states and $u$ is the input of the system, $w(t)$ clarifies the disturbances applied to the system's input and output affected by the random noise $v(t)$. It will be presupposed that $w(t)$ and $v(t)$ are not linked and zero-mean stochastic processes. Statistically, the stochastic operation $w(t)$ and $v(t)$ are characterized by the covariance matrices $Q$ and $R$ respectively. Therefore, $Q$ and $R$ can be expressed as [13]:

$\left\{\begin{array}{l}Q=\operatorname{cov}(w)=E\left\{w w^{T}\right\} \\ R=\operatorname{cov}(v)=E\left\{v v^{T}\right\}\end{array}\right.$.

\section{Simulation of the sensorless input-output linearization control for the PMSM}

The Input-Output linearization control strategy of the PMSM is used in the simulation in the healthy and faulty states. The characteristics of the motor are given in the Appendix.

Fig. 3 presents the global diagram of the sensorless Input-Output linearization control of the PMSM using

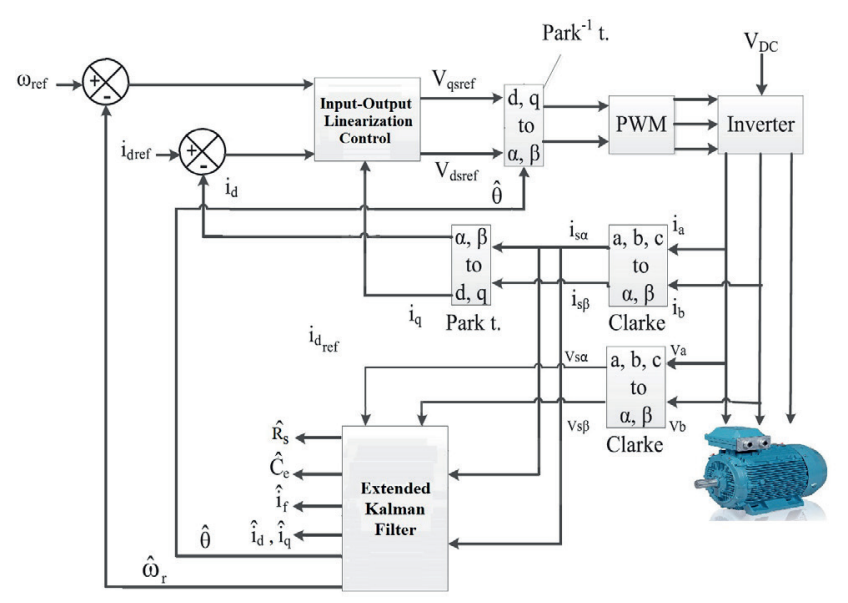

Fig. 3 Global diagram of the sensorless Input-Output linearization control of the PMSM 
the EKF observer, based on the dynamic model of the machine in the healthy and faulty states.

\subsection{Simulation results and discussion}

In order to test the effectiveness and the performance of the sensorless input-output linearization control of the PMSM in the simulation using the EKF observer, diverse tests have been realized in the healthy and faulty states, such as the start-up with no load and the load torque application at $t=0.5 \mathrm{~s}$, then at $t=1 \mathrm{~s}$ in which the machine operates in the faulty state with $3 \%$ of the winding turns fault in the phase $(a)$ where the fault resistance is $r_{f}=0 \Omega$. Fig. 4 shows the characteristics of the sensorless Input-Output linearization control of the PMSM in the healthy and faulty states. The speed follows its reference after a transient state which lasts $0.08 \mathrm{~s}$ and decreases slightly at the time $t=0.5 \mathrm{~s}$ of the load application. A good estimated speed is noticed, where the real and estimated speeds show a perfect superposition. The electromagnetic torque presents a fast and accurate dynamic, while the three phase currents illustrate a pure sinusoidal waveform during the load application. The estimated currents $\left(I_{d}, I_{q}\right)$ show an accurate estimation also, the $I_{q}$ current follows the evolution of the electromagnetic torque while $I_{d}$ is maintained constant. At the time $(t=1 \mathrm{~s})$, $3 \%$ of the winding turns fault in the phase $\left(a_{s}\right)$ where the fault resistance is $r_{f}=0 \Omega$. It's noticed that the inter-turn short circuit fault does not affect the rotor speed and the torque responses, due to the closed-loop control which masks compensates the fault effect. The amplitude of the fault current if after the fault occurrence is not constant and the quadratic current $I_{q}$ is affected by the defect through the appearance of the oscillations.

\subsection{Stator resistance estimation via the EKF}

The next test is considered for the healthy and faulty states of the PMSM operating at full load. The variation of this parameter can be exploited for the fault detection. Fig. 5 shows the estimation of $R_{s}$. The real value of the stator resistance decreases according to the fault considered at $t=1 \mathrm{~s}$.

The results show an accurate estimation in the steady state. Therefore, the decreasing values of the stator resistance are produced by the inter-turn short circuit; therefore, the off-line diagnosis is necessary. The next section shows the FFT analysis of the electrical characteristics of the PMSM.

\subsection{FFT analysis for the inter-turn fault diagnosis}

The Fast Fourier Transformer (FFT) is known as a traditional method for the rotary machine fault detection. The spectrum analysis is applied to the quadratic and the stator current in the healthy and faulty states of the PMSM Fig. 6. In a stationary state, the FFT analysis is used to characterize the fault for different numbers of the inter-turn short circuit.

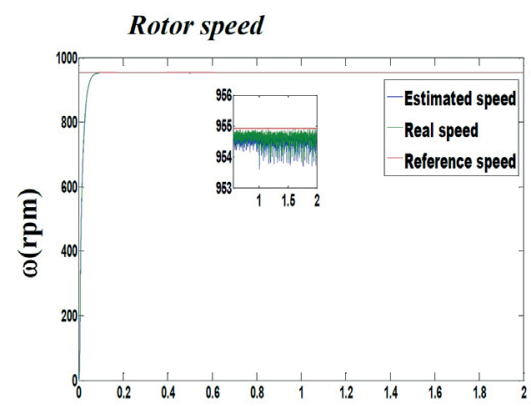

Time (s)

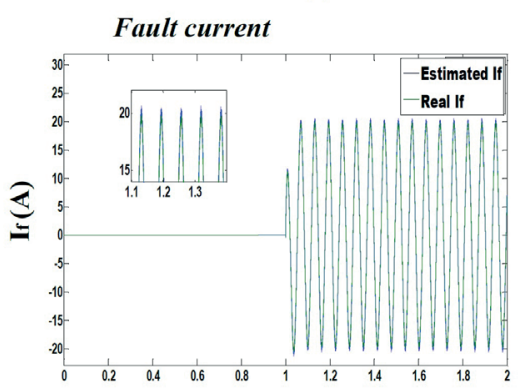

Time (s)

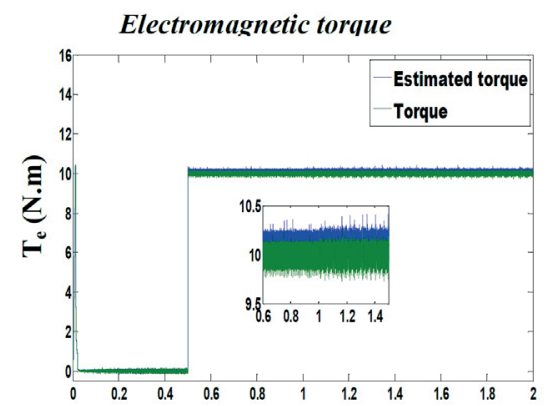

Time (s)

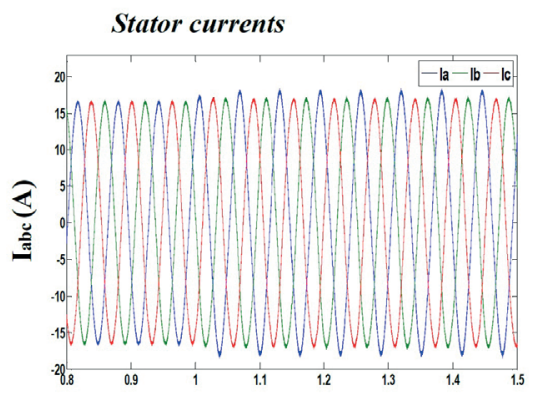

Time (s)

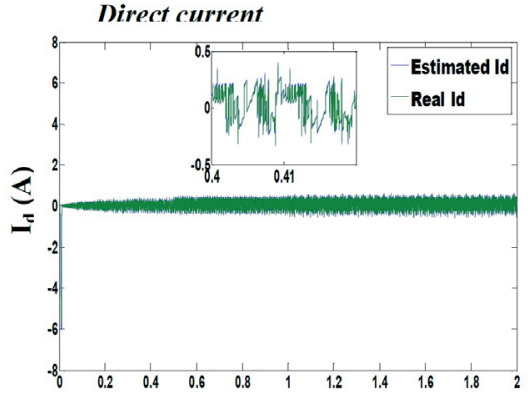

Time

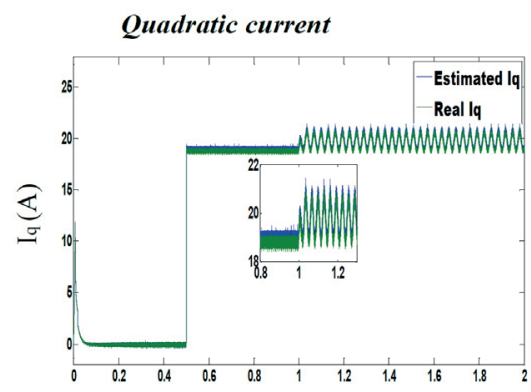

Time (s)

Fig. 4 The electrical and a mechanical characteristics of the sensorless input-output linearization control of the PMSM in the healthy and faulty states

$$
\left(\mu=3 \%, r_{f}=0 \Omega\right)
$$



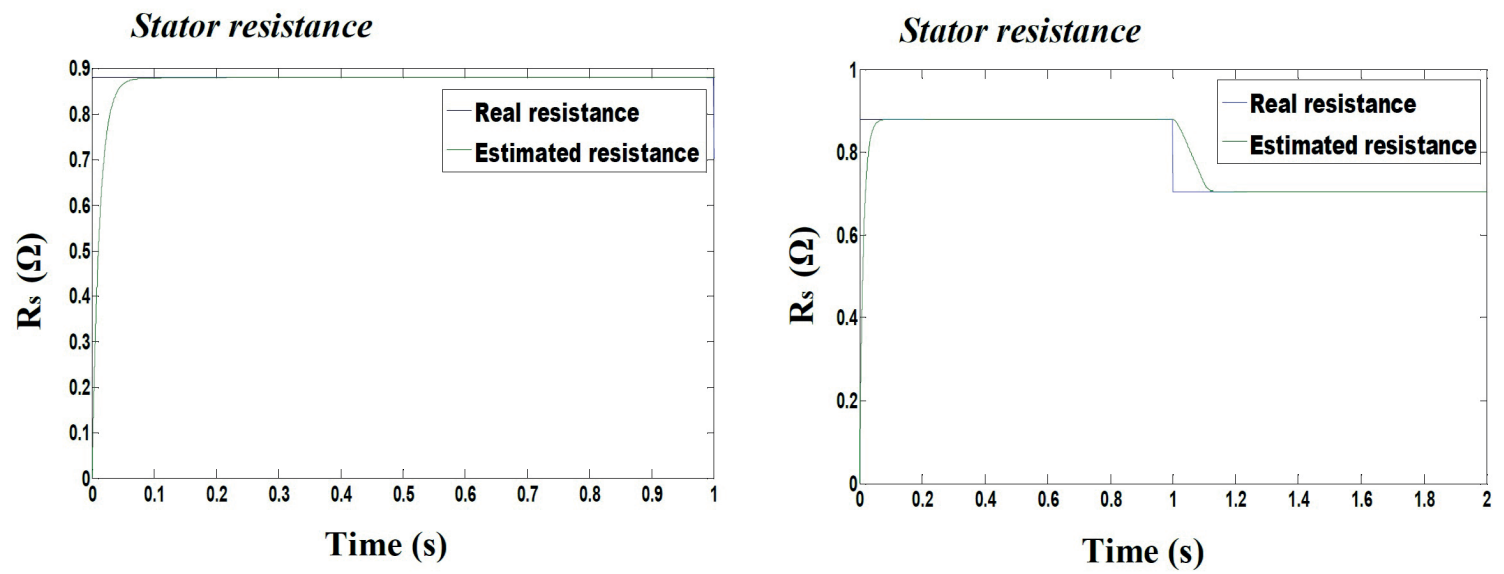

Fig. 5 The evolution of the stator resistance estimation and its errors for the PMSM (a) healthy state (b) $\mu=3 \%, r_{f}=0 \Omega$ at $t=1 \mathrm{~s}$.
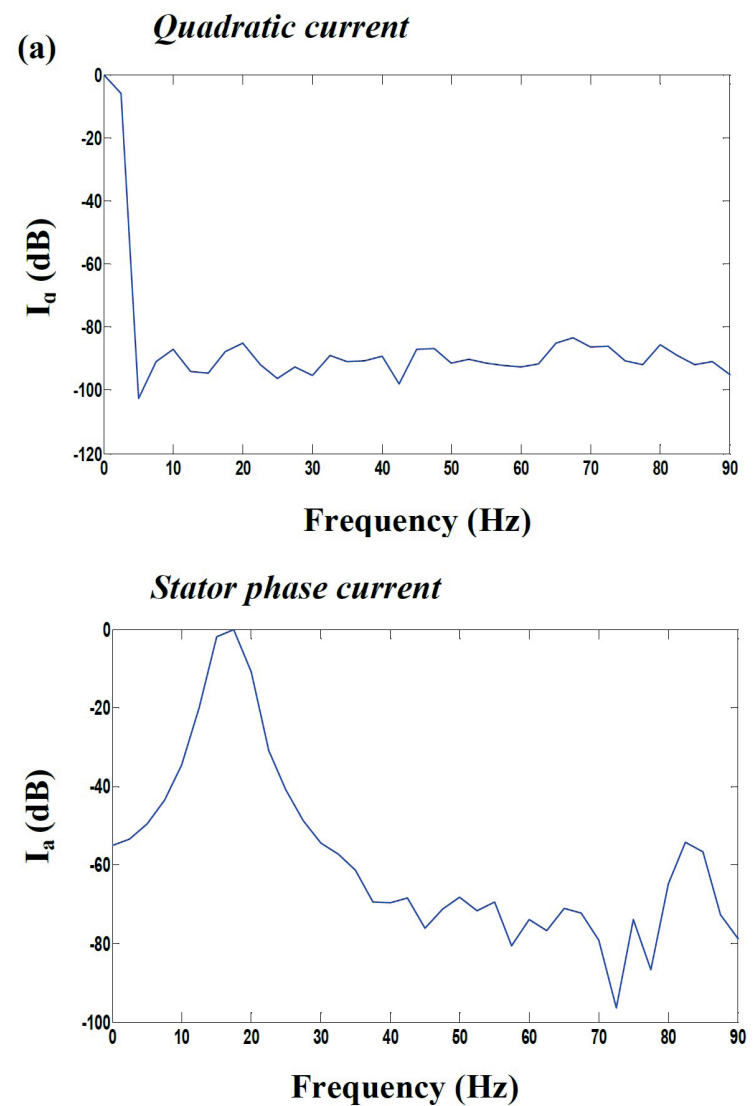

(b) Quadratic current

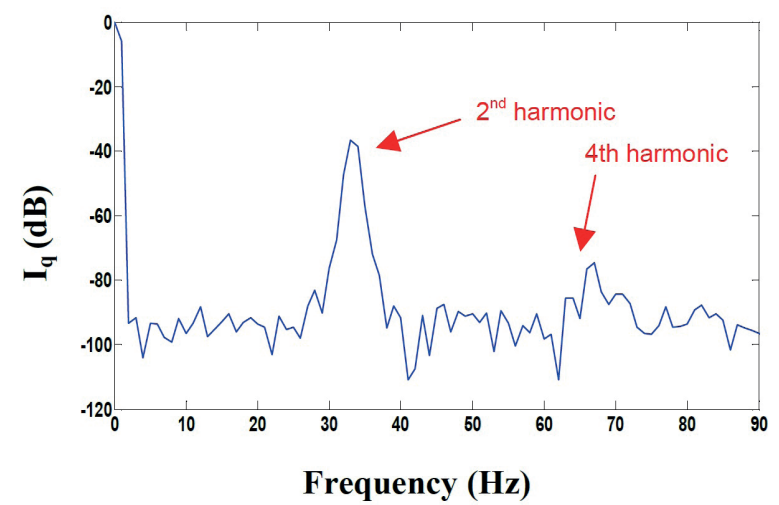

Stator phase current

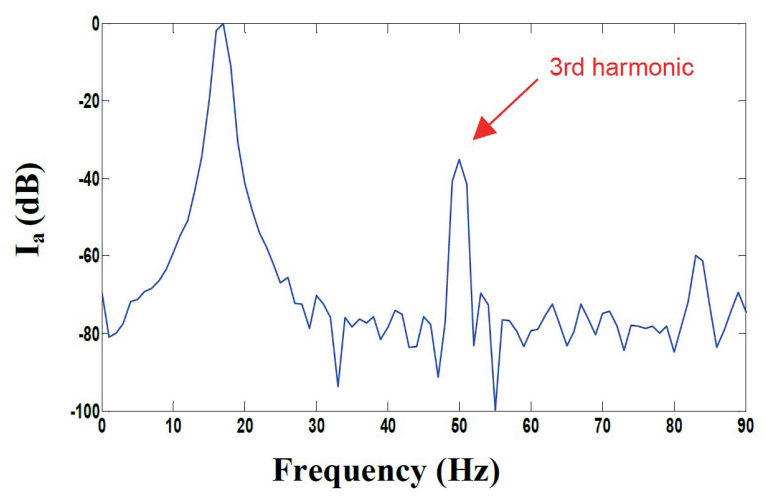

Fig. 6 The FFT analysis of the electrical characteristics of the machine (a) Healthy state (b) Faulty state: $\mu=3 \%, r_{f}=0 \Omega$.

The measurements of the harmonic amplitudes of the stator phase current in the healthy and faulty states for the different values of the fault severity $\mu=(1 \%, 2 \%, 3 \%)$, and the fault resistance $r_{f}=(0 \Omega, 5 \Omega, 10 \Omega)$ are illustrated in Table 1.

Table 1 shows the amplitudes of the harmonic increases with the severity of the fault and the inversely proportional to the values of the fault resistance, it can be said that the currents became an appropriate quantity for the fault diagnosis.

The spectrum analysis with the FFT for the quadratic current $I_{q}$ shows the magnitude of the harmonic at $2 f_{s}$ which correspond to the harmonics of defects, and the $3^{\text {rd }}$ harmonic for the stator current increases in the faulty state. The amplitude of the harmonic increases with the severity of the fault and decreases with the values of the fault resistance. 
Table 1 The FFT analysis of the stator and quadratic currents for the different values of the severity of the fault and fault resistance

\begin{tabular}{lcccccc}
\hline & \multicolumn{3}{c}{ Severity of fault with $r_{f}=0.1 \Omega$} & \multicolumn{3}{c}{ Faulty resistances with $\mu=3 \%$} \\
\hline & $1 \%$ & $2 \%$ & $3 \%$ & $10 \Omega$ & $5 \Omega$ & $0 \Omega$ \\
$\mathbf{3}^{\text {rd }}$ harmonic of " $\boldsymbol{I}_{s a}$ " in Healthy sate & -73.53 & -73.53 & -73.53 & -73.53 & -73.53 & -73.53 \\
$\mathbf{3}^{\text {rd }}$ harmonic of " $\boldsymbol{I}_{s \text { " }}$ " in Faulty state & -47.42 & -34.67 & -30.87 & -60.53 & -55.46 & -30.93 \\
$\mathbf{2}^{\text {nd }}$ harmonic of " $\boldsymbol{I}_{q}$ " in Healthy state & -89.87 & -89.87 & -89.87 & -89.87 & -89.87 & -89.87 \\
$\mathbf{2}^{\text {nd }}$ harmonic of " $\boldsymbol{I}_{q}$ " in Faulty state & -49.92 & -41.37 & -35.29 & -73.49 & -54.64 & -36.55 \\
\hline
\end{tabular}

6.4 DWT for the Inter-Turn short circuit fault diagnosis

The DWT is an efficient and powerful technique which provides the time-frequency representation of a non-stationary signal with a better time resolution than the FFT [23].

Before the application of the DWT, first, we have to select the type of the mother wavelet and the number of the decomposition levels.

\subsubsection{Selection of the mother wavelet}

There are several wavelet families with different mathematical properties that have been developed. In our case, we have used Daubechies-44 as the mother wavelet for the DWT analyses.

\subsubsection{Specification of the Number of \\ Decomposition levels}

The decomposition level $N_{f}$ depends on the sampling rate $f_{s}$ and on the frequency $f$. It can be calculated by the expression

$$
\left.N_{f}\right\rangle \operatorname{int}\left(\frac{\log \left(\frac{f}{f_{s}}\right)}{\log (2)}\right)+1 \text {. }
$$

Considering $f=10000$ samples $/ \mathrm{sec}$ and $f_{s}=50 \mathrm{~Hz}$, the frequency bands associated with each wavelet signal are shown in Table 2.

The Daubechies wavelets of different orders are used to decompose the stator current.

Fig. 7 shows the details and the approximation signals (d7, d8, d9, and a12) obtained by db44 in the healthy and faulty states of the machine.

Fig. 7 shows the DWT of the phase stator current, where, the evolution of the fault is observed in the frequency

Table 2 The frequency levels of the wavelet coefficients.

\begin{tabular}{lc}
\hline Level & Frequency band $(\mathrm{Hz})$ \\
\hline a12 & $0-1.22$ \\
d9 & $09.765-19.531$ \\
d8 & $19.531-39.062$ \\
d7 & $39.062-78.125$ \\
\hline
\end{tabular}

bands for the relative signal through the coefficients (a12, $\mathrm{d} 7, \mathrm{~d} 8$, and $\mathrm{d} 9$ ). It is shown at the comparison of the details and the approximation signals when the fault resistance is fixed to $0.1 \Omega$ and for the different values of the fault severity $\mu=(1 \%, 2 \%, 3 \%)$ that the amplitude of the coefficients a1 2 and $\mathrm{d} 9$ are increased due to the frequency components located at $3 f_{s}$ Table 2 . Therefore, the DWT technique is a very effective tool for the detection of the inter-turn short circuit in the PMSM.

\section{Conclusion}

The studied defect in this work is the inter-turn short circuit fault in the stator winding of the permanent magnet synchronous motor (PMSM). Considering the inter-turn short circuit, a dynamic model has been presented for the control of the machine. The EKF observer is used to estimate the rotor speed in both the healthy and faulty states of the machine. The estimation of the stator resistance has been done also for the fault detection in the transient and steady states of the PMSM.

Two signal approaches for the fault diagnosis have been used, which are the FFT for the stationary state and the DWT for the non-stationary state. The analyzed quantities using those two approaches are the stator current and the quadratic current. The EKF observer has an accurate estimation for the stator resistance $R_{s}$ in both the healthy and faulty states. Furthermore, it can be employed as a fault indicator in the transient and steady states.

The FFT and the DWT analyses have been used to confirm if the variation of the stator resistance is occurred due to the inter-turn fault or by the load application or any other external disturbances. It should be noted that the stator phase current and the quadratic current gave good informations about the presence of the fault, unlike the rotor speed, which has been affected by the closed-loop control regulation.

The FFT analysis has advantages in the steady state only. Hence, the use of the DWT method is a very effective and reliable technique for the diagnosis and detection of the inter-turn short circuit fault in the PMSM, in which the failure can be detected while the motor is operating, particularly in the case of the inter-turn fault. 


\section{(a) Healthv state}

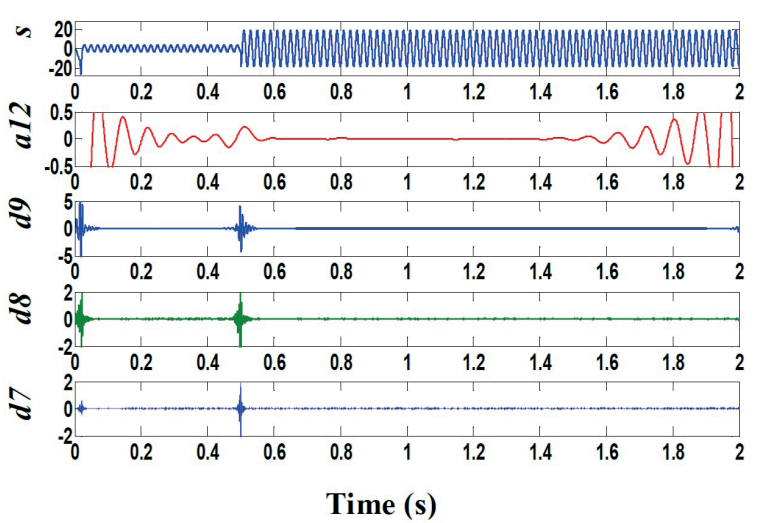

(c) Faulty state $:\left(r_{f}=0.1 \Omega, \mu=2 \%\right)$

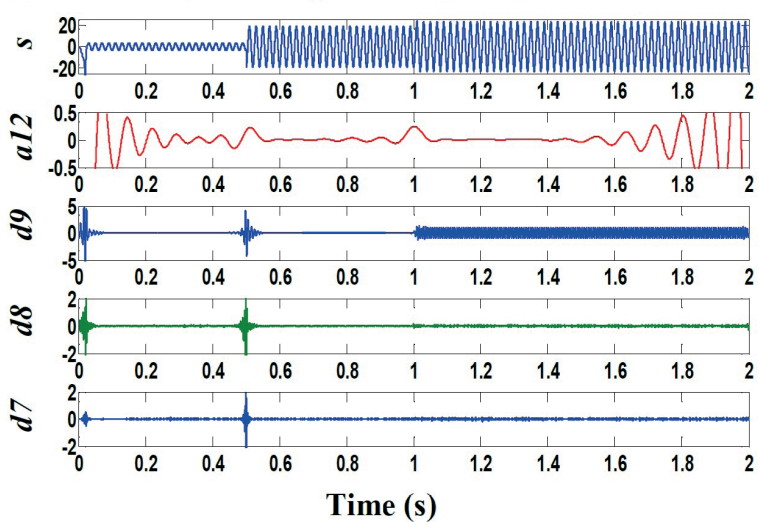

(b) Faulty state $:\left(r_{f}=0.1 \Omega, \mu=1 \%\right)$

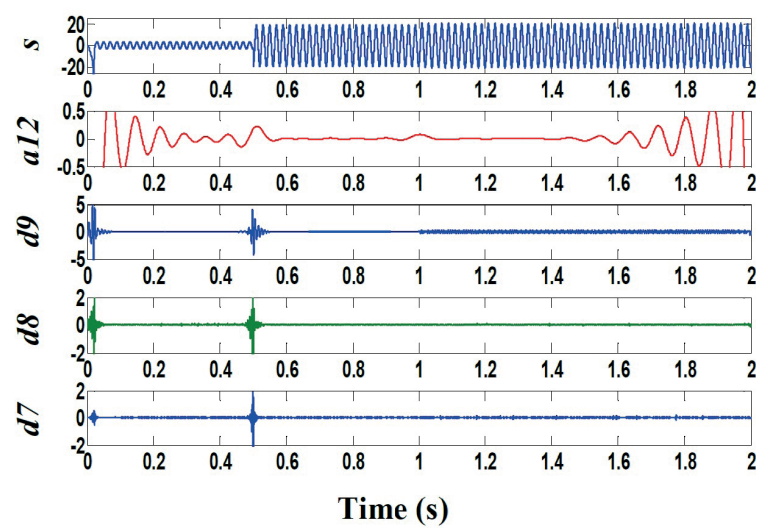

(d) Faulty state $:\left(r_{f}=0.1 \Omega, \mu=3 \%\right)$

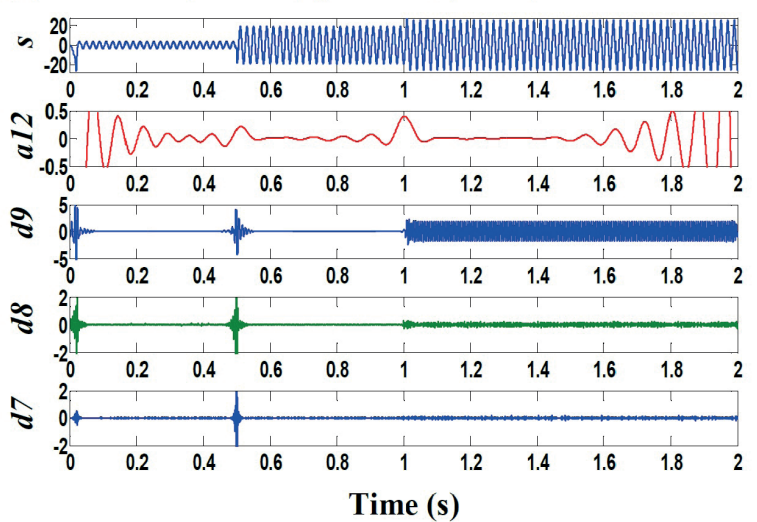

Fig. 7 The DWT analysis of the stator current envelope: (a) Healthy state, (b) Faulty state $\mu=1 \%, r_{f}=0.1 \Omega$ (c) Faulty state $\mu=2 \%, r_{f}=0.1 \Omega$ (d) Faulty state $\mu=3 \%, r_{f}=0.1 \Omega$

\section{Appendix}

PMSM parameters used in the simulation results:
$P_{n}$

$I_{n}$

$p$

$N_{s}$

$R_{s}$

\section{Rated power}

Rated current

$5 \mathrm{~kW}$

$19 \mathrm{~A}$

Number of pole pairs

4

40

$0.88 \Omega$
$L_{s}$

$\Omega_{s}$

$J$

$f$

$\Phi_{f}$
Stator inductance

Synchronous speed

Inertia moment

Coefficient of damping

Flux established by rotor
$2.82 \mathrm{mH}$

$1000 \mathrm{rpm}$

$0.0006 \mathrm{~kg} . \mathrm{m}^{2}$

$0.007 \mathrm{Nm} / \mathrm{rad} / \mathrm{s}$

$0.108 \mathrm{~Wb}$

\section{References}

[1] Bechkaoui, A., Ameur, A., Bouras, S., Ouamrane, K. "Hybrid Control Using Adaptive Fuzzy Sliding Mode for Diagnosis of Stator Fault in PMSM", Periodica Polytechnica Transportation Engineering, 44(3), pp. 172-180, 2016. https://doi.org/10.3311/PPtr.8242

[2] Huangfu, Y., Wang, S., Wang, S., Li, H., Yuan, D., Wang, S., Di Rienzo, L. "Macro-modeling and passivity enforcement for PMSM winding", COMPEL - The international journal for computation and mathematics in electrical and electronic engineering, 36(6), pp. 1729-1738, 2017.

https://doi.org/10.1108/COMPEL-12-2016-0572
[3] Kiselev, A., Kuznietsov, A., Leidhold, R. "Model based online detection of inter-turn short circuit faults in PMSM drives under

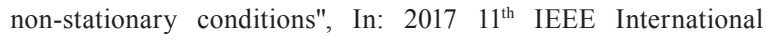
Conference on Compatibility, Power Electronics and Power Engineering, CPE-POWERENG, Cadiz, Spain, 2017, pp. 370-374. https://doi.org/10.1109/CPE.2017.7915199

[4] Vajsz, T., Számel, L., Rácz, G. "A Novel Modified DTC-SVM Method with Better Overload-capability for Permanent Magnet Synchronous Motor Servo Drives", Periodica Polytechnica Electrical Engineering and Computer Science, 61(3), pp. 253-263, 2017. https://doi.org/10.3311/PPee.10428 
[5] Keskes, H., Braham, A. "Recursive Undecimated Wavelet Packet Transform and DAG SVM for Induction Motor Diagnosis", IEEE Transactions on Industrial Informatics, 11(5), pp. 1059-1066, 2015. https://doi.org/10.1109/TII.2015.2462315

[6] Kalas, D., Pretl, S., Reboun, J., Soukup, R., Hamacek, A. "Novel Technology for Thermal Testing of Glove", Periodica Polytechnica Electrical Engineering and Computer Science, 62(4), pp. 165-171, 2018. https://doi.org/10.3311/PPee.13264

[7] Farkas, B., Veszprémi, K. "Regenerative Cascaded Cell Inverter with Active Filter", Periodica Polytechnica Electrical Engineering and Computer Science, 59(2), pp. 36-42, 2015. https://doi.org/10.3311/PPee.8165

[8] Pálfi, V., Kollár, I. "Limitations of the noise model of round off for the FFT", Periodica Polytechnica Electrical Engineering, 53(3-4), pp. 179-185, 2010.

https://doi.org/10.3311/pp.ee.2009-3-4.09

[9] Wang, Y., Zhang, F., Zhang, S., Yang, G. "A novel diagnostic algorithm for $\mathrm{AC}$ series arcing based on correlation analysis of high-frequency component of wavelet", COMPEL - The international journal for computation and mathematics in electrical and electronic engineering, 36(1), pp. 271-288, 2017. https://doi.org/10.1108/COMPEL-08-2015-0282

[10] Égetö, T., Farkas, B. "Model Reference Adaptive System for the Online Rotor Resistance Estimation in the Slip-Ring Machine Based Test-bench", Periodica Polytechnica Electrical Engineering and Computer Science, 62(4), pp. 149-154, 2018. https://doi.org/10.3311/PPee.12495

[11] Bessous, N., Zouzou, S. E., Bentrah, W., Sbaa, S., Sahraoui, M. "Diagnosis of bearing defects in induction motors using discrete wavelet transform", International Journal of System Assurance Engineering and Management, 9(2), pp. 335-343, 2018. https://doi.org/10.1007/s13198-016-0459-6

[12] de Alencar, R. J. N., Ferreira, A. M. D. "Transformer Inrush Currents and Internal Faults Identification in Power Transformers Using Wavelet Energy Gradient", Journal of Control, Automation and Electrical Systems, 27(3), pp. 339-348, 2016. https://doi.org/10.1007/s40313-016-0236-4

[13] Ahmed, M., Karim, F. M. "Input-output linearization and sliding mode control of a permanent magnet synchronous machine fed by a three levels inverter", Journal of electrical engineering, 57(4), pp. 205-210, 2006.

[14] Virosztek, T., Kollár, I. "Theoretical Limits of Parameter Estimation Based on Quantized Data", Periodica Polytechnica Electrical Engineering and Computer Science, 61(4), pp. 312-319, 2017. https://doi.org/10.3311/PPee.10224
[15] Ameid, T., Menacer, A., Talhaoui, H., Harzelli, I., Ammar, A. "Simulation and real-time implementation of sensorless field oriented control of induction motor at healthy state using rotor cage model and EKF", In: Proceedings of $20168^{\text {th }}$ International Conference on Modelling, Identification and Control, ICMIC 2016, Algiers, Algeria, 2017, pp. 695-700. https://doi.org/10.1109/ICMIC.2016.7804201

[16] Talla, J., Peroutka, J., Blahnik, V., Streit, L. "Rotor and Stator Resistance Estimation of Induction Motor Based on Augmented EKF", In: 2015 International Conference on Applied Electronics (AE), Pilsen, Czech Republic, 2015, pp. 253-258.

[17] Kojabadi, H. M., Abarzadeh, M., Chang, L. "A Comparative Study of Various Methods of IM's Rotor Resistance Estimation", In: 2015 IEEE Energy Conversion Congress and Exposition (ECCE), Montreal, QC, Canada, 2015, pp. 2884-2891. https://doi.org/10.1109/ECCE.2015.7310064

[18] Vaseghi, B., Takorabet, N. "Modelling and study of PM machines with inter-turn fault dynamic model - FEM model", Electric Power Systems Research, 81(8), pp. 1715-1722, 2011. https://doi.org/10.1016/j.epsr.2011.03.017

[19] Harnefors, L., Hinkkanen, M. "Stabilization Methods for Sensorless Induction Motor Drives-A Survey", IEEE Journal of Emerging and Selected Topics in Power Electronics, 2(2), pp. 132-142, 2014. https://doi.org/10.1109/JESTPE.2013.2294377

[20] Titaouine, A., Moussi, A., Benchabane, F., Yahia, K. "Sensorless Nonlinear Control of Permanent Magnet Synchronous Motor Using the Extended Kalman Filtre", Asian Journal of Information Ttechnology, 5(12), pp. 1416-1422, 2006. [online] Available at: http://medwelljournals.com/abstract/?doi=ajit.2006.1416.1422 [Accessed: 05 December 2006]

[21] Janiszewski, D., Muszyński, R. "Sensorless control of PMSM drive with state and load torque estimation", COMPEL - The International Journal for Computation and Mathematics in Electrical and Electronic Engineering, 26(4), pp. 1175-1187, 2007. https://doi.org/10.1108/03321640710756483

[22] Ameid, T., Menacer, A., Talhaoui, H., Harzelli, I. "Rotor resistance estimation using Extended Kalman filter and spectral analysis for rotor bar fault diagnosis of sensorless vector control induction motor", Measurement: Journal of the International Measurement Confederation, 111, pp. 243-259, 2017. https://doi.org/10.1016/j.measurement.2017.07.039

[23] Sakhara, S., Saad, S., Nacib, L. "Diagnosis and detection of short circuit in asynchronous motor using three-phase model", International Journal of System Assurance Engineering and Management, 8(2), pp. 308-317, 2016. https://doi.org/10.1007/s13198-016-0435-1 